\title{
The contribution of symptoms and comorbidities to the economic impact of COPD: an analysis of the German COSYCONET cohort
}

This article was published in the following Dove Press journal: International Journal of COPD

\author{
Margarethe E Wacker,' \\ Katharina Kitzing, ${ }^{1,2}$ Rudolf A \\ Jörres, ${ }^{3}$ Reiner Leidl, ${ }^{1,4}$ Holger \\ Schulz, ${ }^{5}$ Stefan Karrasch, ${ }^{3,5}$ \\ Annika Karch, ${ }^{6}$ Armin Koch, ${ }^{6}$ \\ Claus F Vogelmeier, ${ }^{7}$ Rolf Holle' \\ On behalf of the COSYCONET \\ Study Group
}

'Institute of Health Economics and Health Care Management, Helmholtz Zentrum München $\mathrm{GmbH}$, German Research Center for Environmental Health, Comprehensive Pneumology Center Munich (CPC-M), Member of the German Center for Lung Research, Neuherberg, ${ }^{2}$ Institute for Medical Information Processing, Biometrics and Epidemiology (IBE), LMU Munich, ${ }^{3}$ Institute and Outpatient Clinic for Occupational, Social and Environmental Medicine, ${ }^{4}$ Institute of Health Economics and Health Care Management, Munich Center of Health Sciences, Ludwig-MaximiliansUniversität München, Munich, ${ }^{5}$ Institute of Epidemiology I, Helmholtz Zentrum München GmbH, German Research Center for Environmental Health, Comprehensive Pneumology Center Munich (CPC-M), Member of the German Center for Lung Research, Neuherberg, 'Institute for Biostatistics, Hannover Medical School, Hannover ${ }^{7}$ Department of Medicine, Pulmonary and Critical Care Medicine, University Medical Center Giessen and Marburg, PhilippsUniversity Marburg, Member of the German Center for Lung Research, Marburg, Germany

Correspondence: Margarethe E Wacke Institute of Health Economics and Health Care Management, Helmholtz Zentrum München $\mathrm{GmbH}$, German Research Center for Environmental Health, Ingolstädter Landstraße I, 85764 Neuherberg, Germany Tel +49 89 3I874I66

Email margarethe.wacker@helmholtz-muenchen.de
Background: Although patients with COPD often have various comorbidities and symptoms, limited data are available on the contribution of these aspects to health care costs. This study analyzes the association of frequent comorbidities and common symptoms with the annual direct and indirect costs of patients with COPD.

Methods: Self-reported information on 33 potential comorbidities and symptoms (dyspnea, cough, and sputum) of 2,139 participants from the baseline examination of the German COPD cohort COSYCONET was used. Direct and indirect costs were calculated based on self-reported health care utilization, work absence, and retirement. The association of comorbidities, symptoms, and COPD stage with annual direct/indirect costs was assessed by generalized linear regression models. Additional models analyzed possible interactions between COPD stage, the number of comorbidities, and dyspnea.

Results: Unadjusted mean annual direct costs were $€ 7,263$ per patient. Other than COPD stage, a high level of dyspnea showed the strongest driving effect on direct costs $(+33 \%)$. Among the comorbidities, osteoporosis $(+38 \%)$, psychiatric disorders $(+36 \%)$, heart disease $(+25 \%)$, cancer $(+24 \%)$, and sleep apnea $(+21 \%)$ were associated with the largest increase in direct costs $(p<0.01)$. A sub-additive interaction between advanced COPD stage and a high number of comorbidities reduced the independent cost-driving effects of these factors. For indirect costs, besides dyspnea $(+34 \%)$, only psychiatric disorders $(+32 \%)$ and age $(+62 \%$ per 10 years $)$ were identified as significant drivers of costs $(p<0.04)$. In the subsequent interaction analysis, a high number of comorbidities was found to be a more crucial factor for increased indirect costs than single comorbidities.

Conclusion: Detailed knowledge about comorbidities in COPD is useful not only for clinical purposes but also to identify relevant cost factors and their interactions and to establish a ranking of major cost drivers. This could help in focusing therapeutic efforts on both clinically and economically important comorbidities in COPD.

Keywords: COPD, comorbidities, symptoms, direct and indirect costs, health care

\section{Introduction}

COPD is globally one of the leading causes of morbidity and mortality. ${ }^{1}$ The aging global population and the ongoing exposure to risk factors is expected to further increase the prevalence of COPD.

Previous studies have revealed that COPD has a very high economic burden because of its excess health care utilization and the impact on work absence and premature retirement. $^{2-7}$ For the countries of the European Union, the direct costs attributable to COPD were estimated as $€ 23.3$ billion in 2011 , and indirect costs as $€ 25.1$ billion, 
although with the acknowledgement of a significant underestimation. ${ }^{6}$ For Germany, the reported annual excess costs per COPD case for the year 2012 ranged between $€ 2,595$ and $€ 8,924$ for direct costs, and between $€ 8,621$ and $€ 27,658$ for indirect costs in Global initiative for Obstructive Lung Disease (GOLD) stages 1 and 4 , respectively. ${ }^{3}$ With its increasing prevalence, the direct and indirect costs of COPD are expected to rise substantially., 4,9

Besides dyspnea, cough, and sputum production as the leading symptoms, ${ }^{1}$ comorbidities have been shown to increase the clinical impact of the lung disorder and have gained increased interest in recent years. A broad range of coexisting diseases occur frequently in patients with COPD, including respiratory, cardiovascular, metabolic, and mental. ${ }^{10}$ Comorbid conditions have been shown to reduce patients' health-related quality of life ${ }^{11,12}$ and alter their disease course and survival. ${ }^{13,14}$ Furthermore, comorbid conditions are responsible for increased health care utilization in patients with $\mathrm{COPD}^{15-17}$ and thus increased total health care costs. ${ }^{3,18,19}$ The prevalence of many of these comorbidities also increases with age, and so the aging population is likely to result in further increases in these costs. However, there is high heterogeneity among studies describing the effects of comorbidities on health care utilization and costs. Some studies focused on one comorbid condition only, ${ }^{20}$ while others considered a limited spectrum of comorbidities ${ }^{3,21}$ or special treatment situations only, ${ }^{22}$ with the majority of studies focusing on total health care costs, rather than on COPD-related costs.

Furthermore, few studies have examined the cost-driving effect of COPD symptoms such as dyspnea. ${ }^{23-25}$ High symptom burden has been shown to be associated with increased health care utilization and work impairment ${ }^{23}$ as well as societal costs. ${ }^{24,25}$ However, these studies focused on dyspnea only or used an aggregated level of symptoms to define their burden.

Taken together, there is a lack of economic studies investigating the impact of a broad range of comorbid conditions and distinct symptoms on direct and indirect costs in a large COPD population. There are even fewer studies that put the effects of comorbid conditions on costs into the context of COPD severity. However, from a public health perspective, there is a substantial need on detailed knowledge about the cost-driving effects in patients with COPD to identify starting points for reducing disease burden, and finally, for cost containment.

Therefore, the aim of this study was to identify the role of the most prevalent comorbidities and symptoms as cost-driving factors in COPD and to consider possible interactions between the degree of airflow limitation, comorbidities, and symptoms.

\section{Methods}

\section{Data and study design}

This analysis is based on data from the baseline visit of the German COPD cohort COSYCONET (German COPD and Systemic Consequences - Comorbidities Network). In total, 2,741 patients with a clinical COPD diagnosis were included in this prospective, observational, multicenter cohort study between 2010 and 2013. Inclusion criteria were age $\geq 40$ years and physician-diagnosed COPD. Subjects with lung cancer, or who had undergone lung volume reduction or lung transplantation, or who had experienced a moderate or severe exacerbation within the last 4 weeks, or who had physical or cognitive impairment were excluded. Participants were recruited from inpatient and outpatient health care providers and patient groups and by media campaigns and examined in 31 study centers nationwide in Germany. Detailed information on the cohort has been given elsewhere. ${ }^{26,27}$

\section{COPD definition and lung function}

For this analysis, COPD was defined according to GOLD as a forced expiratory volume in 1 second to forced vital capacity ratio $\left(\mathrm{FEV}_{1} / \mathrm{FVC}\right)<0.7$, based on post-bronchodilator spirometry. ${ }^{1}$ For $\mathrm{FEV}_{1}$, percentage predicted values according to the Global Lung Function Initiative were used for spirometric severity assessment: ${ }^{28}$ COPD GOLD stage 1 was defined as $\mathrm{FEV}_{1} \geq 80 \%$ predicted, stage 2 as $50 \% \leq \mathrm{FEV}_{1}<80 \%$, stage 3 as $30 \% \leq \mathrm{FEV}_{1}<50 \%$, and stage 4 as $\mathrm{FEV}_{1}<30 \%$.

Twenty patients with missing information on GOLD stages and 430 without showing an airflow limitation $\left(\mathrm{FEV}_{1} / \mathrm{FVC} \geq 0.7\right)$ in spirometry were excluded, as were 152 participants with alpha-1-antitrypsin deficiency, who may differ in their comorbidity profile and bias cost estimates, in particular if the very high costs of substitution therapy are included. ${ }^{29}$

\section{Calculation of direct and indirect costs}

All cost calculations were performed from a societal perspective for the price year 2012 .

Information on all-cause health care utilization was assessed via standardized patient interviews and questionnaires, comprising the number of inpatient hospital days, of inpatient and outpatient days in rehabilitative care, and of physiotherapeutic treatments in the last 12 months. The number of physician visits (split into 13 specializations) 
was captured over the last 3 months, and was extrapolated to 12 months. Annual costs per subject were calculated by multiplying all individual utilization frequencies by standardized German unit costs for the price year 2012 as published by Bock et al. ${ }^{30}$

Detailed information on unit costs can be found in Table S1.

The standardized patient interviews assessed the intake of prescribed pharmaceuticals during the previous week including their national drug code Information on Defined Daily Doses, and this information was used for the estimation of mean annual dosages,${ }^{31}$ with annual costs calculated based on pharmacy retail prices in 2012. ${ }^{32}$ Vitamins, dietary supplements, non-pharmacy medicines, and over-the-counter pharmaceuticals were excluded.

Indirect costs in terms of productivity losses as a consequence of temporary inability to work or premature retirement were considered for participants under the regular retirement age of 65 years, according to the human capital approach. Mean annual German labor costs $(€ 37,126)$ were used to price premature retirement. ${ }^{33}$ For temporary inability to work of those who reported to take part in the labor market, the number of absence days in the last 12 months due to illness was multiplied by average costs of $€ 177$ per working day (annual labor costs of $€ 37,126$ divided by the 210 working days in $2012^{34}$ ).

\section{Comorbidities and symptoms}

Information on a list of 33 possible comorbid conditions was assessed by asking all participants during the examination, "Has a physician ever diagnosed you with one of the following diseases?" In seven participants with missing information on single comorbidities, the answer was set to "no".

The presence of cough and sputum production was defined by the first and second question of the COPD Assessment Test (CAT). ${ }^{35}$ The response options for each symptom were dichotomized, and an answer $\geq 3$ (on a scale of 0-5) was counted as "yes". Dyspnea was measured by the modified Medical Research Council (mMRC) dyspnea scale. The response options for dyspnea were also dichotomized, and an answer with $\mathrm{mMRC} \geq 2$ (on a scale of 0-4) was used for separating less vs more breathlessness. ${ }^{1}$

\section{Covariables}

Information on age, sex, smoking status, body mass index (BMI), and level of school education (basic, secondary, and higher) was assessed in standardized interviews, questionnaires, and examinations and considered as covariables.
Smoking status was categorized into current, former, and never smoker. Four participants with missing information on smoking status were counted as former smokers, since this was the most frequent category.

\section{Statistical analysis}

Baseline characteristics, comorbidities, and symptoms of the total study population were summarized descriptively, and compared using analysis of variance for continuous variables and chi-square tests for categorical variables.

In a first step, generalized linear regression models included all single comorbidities with a prevalence $\geq 10 \%$ and the three symptom types (low vs high levels of dyspnea, cough, and sputum, respectively) as predictors of direct costs, their cost components (outpatient, hospitalization, medication, and other costs), and indirect costs. All other comorbidities were summarized and considered as an additional count (between 0 and 17 possible comorbidities with a prevalence $<10 \%$ ). For indirect costs, only subjects $<65$ years participating regularly in the labor market or reporting premature retirement were considered $(n=788)$.

In a second step, additional regression models for direct and indirect costs were performed to study possible interactions between the three predictors COPD GOLD stage 1-4, comorbidities, and dyspnea (cough and sputum production did not show statistically significant effects in the first step). These variables were dichotomized, as follows: low extent of airflow limitation (GOLD 1/2) vs high extent (GOLD 3/4), low $(\leq 3)$ vs high $(>3)$ number of comorbidities, and low (mMRC 0-1) vs high (mMRC 2-4) level of dyspnea. A simple comorbidity count was used (between 0 and 33 possible comorbidities), dichotomized according to its median (=3) as cut-off, which is an approach that has been shown previously to be a good proxy for the burden of comorbidities. ${ }^{36}$

All regression models included age group, sex, level of school education, smoking status, and BMI category as potential confounders. Since cost data typically follow a right-skewed distribution with positive values only, regression models assuming a gamma distribution and log-link were employed. An amount of $€ 1$ was allocated for all observations with zero costs for modeling. Resulting estimates can be interpreted as factors due to the log-link. Adjusted mean costs for different groups were calculated via recycled predictions with 1,000 bootstrap replications for $95 \% \mathrm{CI}$. The significance for all statistical tests was defined at $p<0.05$. Statistical analyses were performed using SAS software, version 9.3 (SAS Institute Inc., Cary, NC, USA). 


\section{Ethical approval}

The COSYCONET study complies with the Declaration of Helsinki and Good Clinical Practice Guidelines and has been approved by the ethics committee of the medical faculty of the Philipps-University Marburg, by the local ethics committees of the participating centers (a list of all participating study centers can be found at http://www.asconet.net/html/ cosyconet/studzent), and by the concerned data security authority (data security agency of the federal states of Hesse, Baden-Württemberg, Lower-Saxony, and Saarland).

Written informed consent was obtained from all study participants.

\section{Results}

\section{Characteristics of the study sample}

Table 1 shows the baseline characteristics of the study population, comprising 2,139 patients with COPD. The mean age was 65.4 years, with $61.1 \%$ being male. Most of the participants were in GOLD stage 2 or 3 . High levels of dyspnea were reported by $48.5 \%$ of participants, with $46.7 \%$ reporting sputum production and $44.9 \%$ cough; $26.0 \%$ of participants did not have any symptoms.

Participants reported a mean number of 3.7 comorbidities. The prevalence of all 33 comorbid conditions studied is shown in Figure 1. With a prevalence of $38.7 \%$, osteoarthritis was the most commonly reported comorbidity, followed by allergies, varicose veins, heart disease, gastritis, and psychiatric disorders.

\section{Direct costs}

Unadjusted mean annual total direct costs (all-cause) were $€ 7,263$ per patient, with $46.8 \%$ due to hospitalization, $34.1 \%$ to prescribed medication, $11.7 \%$ to physician and outpatient hospital visits, and $7.4 \%$ to rehabilitation and physiotherapy (Table 2).

The results of the regression models for total direct costs and their components are presented in Table 3. Higher COPD stage was associated with a statistically significant increase in total direct costs. Compared with COPD stage 1, stage 2 was associated with an increase in costs of $+22 \%$, stage 3 of $+66 \%$, and stage 4 of $+102 \%$ (all $p<0.01$ ). This amplifying effect with GOLD stage was observed for all components of direct costs, except outpatient costs.

Regarding the most prevalent comorbid conditions, osteoporosis showed the main cost-driving effect on total direct costs $(+38 \%)$, followed by psychiatric disorders $(+36 \%)$, heart disease $(+25 \%)$, cancer $(+23 \%)$, sleep apnea $(+21 \%)$, gastric ulcer $(+20 \%)$, cholecystitis/gallstones $(+19 \%)$, migraine
Table I Characteristics of the study population

\begin{tabular}{|c|c|}
\hline Characteristics & \\
\hline $\mathrm{N}$ & 2,139 \\
\hline \multicolumn{2}{|l|}{ Sex } \\
\hline Female & $832(38.9 \%)$ \\
\hline Male & I,307 (6I.I\%) \\
\hline \multicolumn{2}{|l|}{ Age (years) } \\
\hline Mean & $65.4( \pm 8.2)$ \\
\hline$>74$ & $258(12.1 \%)$ \\
\hline $65-74$ & 947 (44.3\%) \\
\hline $55-64$ & $722(33.8 \%)$ \\
\hline$<55$ & $212(9.9 \%)$ \\
\hline \multicolumn{2}{|l|}{ GOLD spirometric stage } \\
\hline Stage I (FEV $\%$ predicted $\geq 80 \%$ ) & 197 (9.2\%) \\
\hline Stage $2(50 \leq \mathrm{FEV}, \%$ predicted $<80)$ & 908 (42.5\%) \\
\hline Stage $3(30 \leq \mathrm{FEV}, \%$ predicted $<50)$ & $810(37.9 \%)$ \\
\hline Stage $4(\mathrm{FEV}, \%$ predicted $<30)$ & $224(10.5 \%)$ \\
\hline \multicolumn{2}{|l|}{ Spirometry } \\
\hline $\mathrm{FEV}_{\text {, }}(\mathrm{L})$, mean & $1.55( \pm 0.6)$ \\
\hline FVC (L), mean & $2.98( \pm 1.0)$ \\
\hline FEV , GLI Z-score & $-2.87( \pm I . I)$ \\
\hline FVC GLI Z-score & $-1.45( \pm 1.3)$ \\
\hline $\mathrm{FEV}_{1} / \mathrm{FVC} \mathrm{GLI}$ Z-score & $-2.97( \pm I . I)$ \\
\hline \multicolumn{2}{|l|}{ Smoking status } \\
\hline Current smoker & $562(26.3 \%)$ \\
\hline Former smoker & $\mathrm{I}, 46 \mathrm{I}(68.3 \%)$ \\
\hline Never smoker & 116 (5.4\%) \\
\hline \multicolumn{2}{|l|}{ BMI $\left(\mathrm{kg} / \mathrm{m}^{2}\right)$} \\
\hline Mean & $26.8( \pm 5.3)$ \\
\hline Underweight (BMI < I8.5) & $76(3.6 \%)$ \\
\hline Normal weight $(I 8.5 \leq \mathrm{BMI}<25)$ & $774(36.2 \%)$ \\
\hline Overweight $(25 \leq \mathrm{BMI}<30)$ & $789(36.9 \%)$ \\
\hline Obese $(\mathrm{BMI} \geq 30)$ & $499(23.3 \%)$ \\
\hline \multicolumn{2}{|l|}{ Education } \\
\hline Basic school education & $1,219(57.0 \%)$ \\
\hline Secondary school education & $557(26.0 \%)$ \\
\hline Higher school education & $363(17.0 \%)$ \\
\hline \multicolumn{2}{|l|}{ Comorbidities } \\
\hline Number of comorbidities, mean & $3.7( \pm 2.5)$ \\
\hline Number of comorbidities, median & $3(2-5)$ \\
\hline Number of comorbidities $\leq 3$ & $\mathrm{I}, \mathrm{I} \mid \mathrm{A}(52.1 \%)$ \\
\hline Number of comorbidities $>3$ & I,025 (47.9\%) \\
\hline \multicolumn{2}{|l|}{ Symptoms ${ }^{\mathrm{b}}$} \\
\hline Cough (CAT $\geq 3$ ) & $954(44.9 \%)$ \\
\hline Sputum (CAT $\geq 3$ ) & $993(46.7 \%)$ \\
\hline Dyspnea (mMRC $\geq 2$ ) & $\mathrm{I}, 027(48.5 \%)$ \\
\hline No symptoms & $557(26.0 \%)$ \\
\hline
\end{tabular}

Notes: Data are mean (SD) or $\mathrm{n}$ (percentage) or median (interquartile range). aPost-bronchodilator spirometry. ${ }^{\circ}$ Thirteen participants had missing CAT scores, and 20 had missing mMRC scale.

Abbreviations: GOLD, Global initiative for Obstructive Lung Disease; FEV, forced expiratory volume in I second; FVC, forced vital capacity; GLI, Global Lung Function Initiative; BMI, body mass index; CAT, COPD Assessment Test; mMRC, modified Medical Research Council.

$(+15 \%)$, and peripheral artery disease $(+14 \%)$, with all $p \leq 0.03$. For the components of direct costs, psychiatric disorders had the highest cost-driving effect regarding outpatient and hospitalization costs, whereas sleep apnea showed 


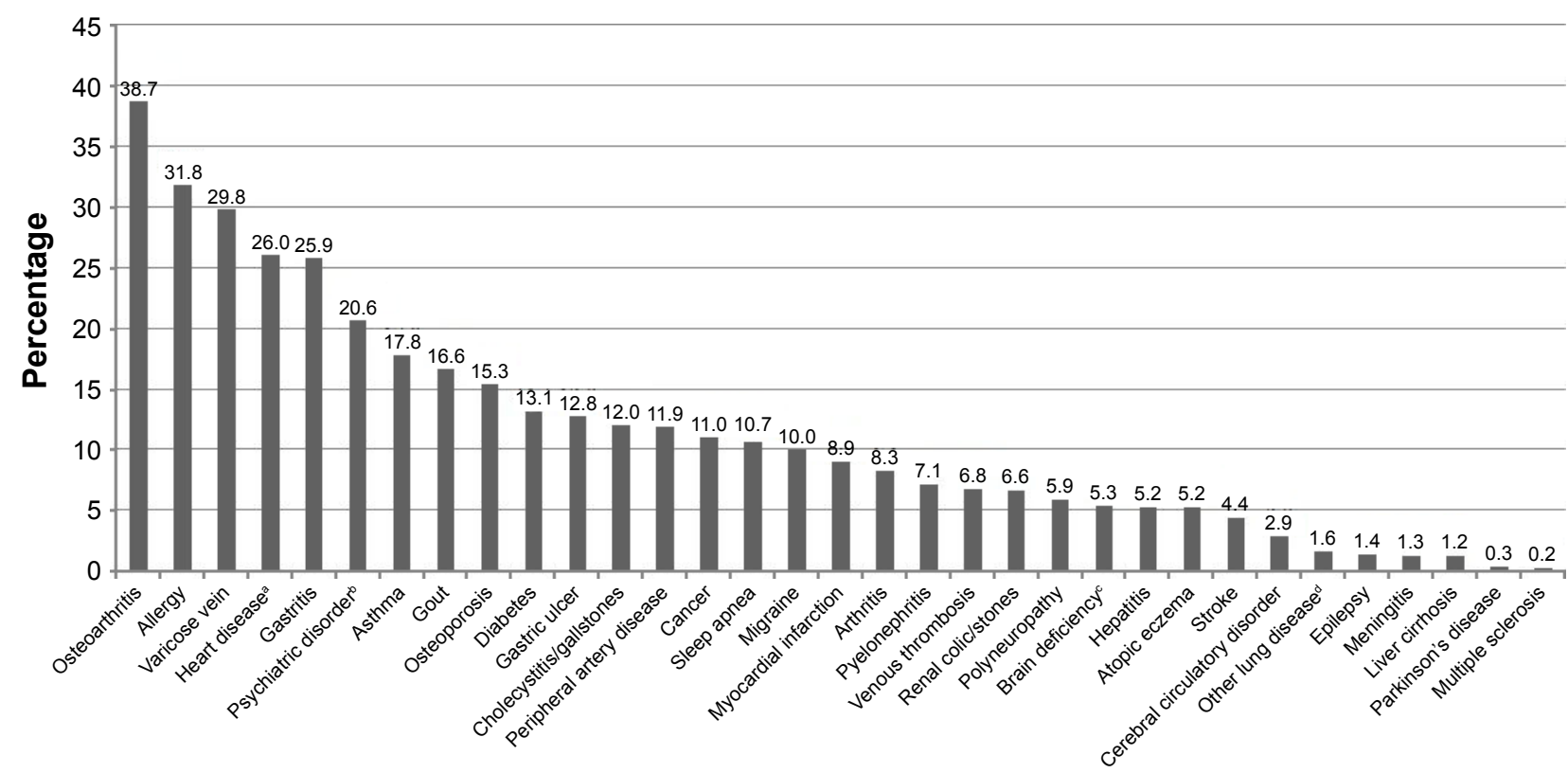

Figure I Lifetime prevalence (\%) of comorbid conditions.

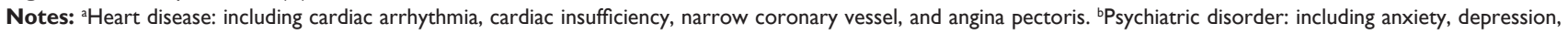
and psychosis. 'Mental deficiency: including weakness of memory, restlessness, disorientation, and confusion. ${ }^{\circledR}$ Other lung disease: fibrosis, sarcoidosis, and bronchiectasis.

the strongest effect on other costs and cancer showed the strongest effect on medication costs.

In terms of symptoms, a high level of dyspnea $(\mathrm{mMRC} \geq 2)$ was associated with an increase in total direct costs of $+33 \%$ $(p<0.0001)$, with significant effects on all cost components. Cough and sputum production (CAT $\geq 3$ ) were not associated with increased direct costs, either total or the cost components.

\section{Indirect costs}

The indirect costs were analyzed in a subgroup of 779 patients $<65$ years with complete information on retirement status or absence days. Unadjusted mean indirect costs of participants $<65$ years were $€ 23,298$, mainly determined by $56 \%$ of this sample being retired prematurely. Besides a high level of dyspnea (+34\%), parameters associated with

Table 2 Unadjusted mean annual direct and indirect costs

\begin{tabular}{|c|c|c|c|}
\hline Cost categories & $\mathbf{n}$ & $\begin{array}{l}\% \text { with } \\
\text { costs }>0\end{array}$ & $\begin{array}{l}\text { Unadjusted costs } \\
(€, 20 I 2)(S D)\end{array}$ \\
\hline Total direct costs & 2,105 & 99.7 & $7,263(9,810)$ \\
\hline Outpatient costs ${ }^{\mathrm{a}}$ & 2,118 & 95.8 & 855 (777) \\
\hline Hospitalization costs & 2,115 & 38.2 & $3,403(8,303)$ \\
\hline Medication costs & 2,139 & 98.2 & 2,475 (3,259) \\
\hline Other direct costs ${ }^{\mathrm{b}}$ & 2,122 & 44.0 & $536(1,145)$ \\
\hline Total indirect costs & 779 & 87.7 & $23,298(16,833)$ \\
\hline
\end{tabular}

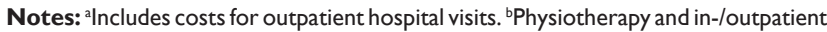
rehabilitation. significantly increased indirect costs were higher age $(+59 \%)$ and psychiatric disorders $(+31 \%)$ (Table 3$)$.

\section{Interactions}

Table 4 shows the results of the regression models considering interactions between dichotomized COPD stage, the number of comorbidities, and dyspnea for direct and indirect costs. Figure 2 depicts the absolute costs of the respective groups of the models. Higher COPD stage, a high number of comorbidities, and a high level of dyspnea were associated with increases of $+69 \%,+83 \%$, and $+43 \%$ in direct costs (all $p<0.0001$ ). There was an additional sub-additive, costreducing effect of having both an advanced COPD stage and a high number of comorbidities $(-28 \%, p=0.0001)$, with the other interactions not reaching statistical significance.

For indirect costs, cost increased with a high number of comorbidities ( $+46 \%$; $p=0.03$ ). The level of dyspnea, GOLD stage, and the interaction terms did not reach statistical significance.

Adjusted mean direct and indirect costs by group (GOLD 1/2 vs GOLD 3/4, low vs high number of comorbidities, low vs high level of dyspnea) are shown in Figure 2.

\section{Discussion}

This study analyzed the cost-driving effects of frequent comorbidities and symptoms, in addition to the level of airflow limitation in patients with COPD. A high level of dyspnea 


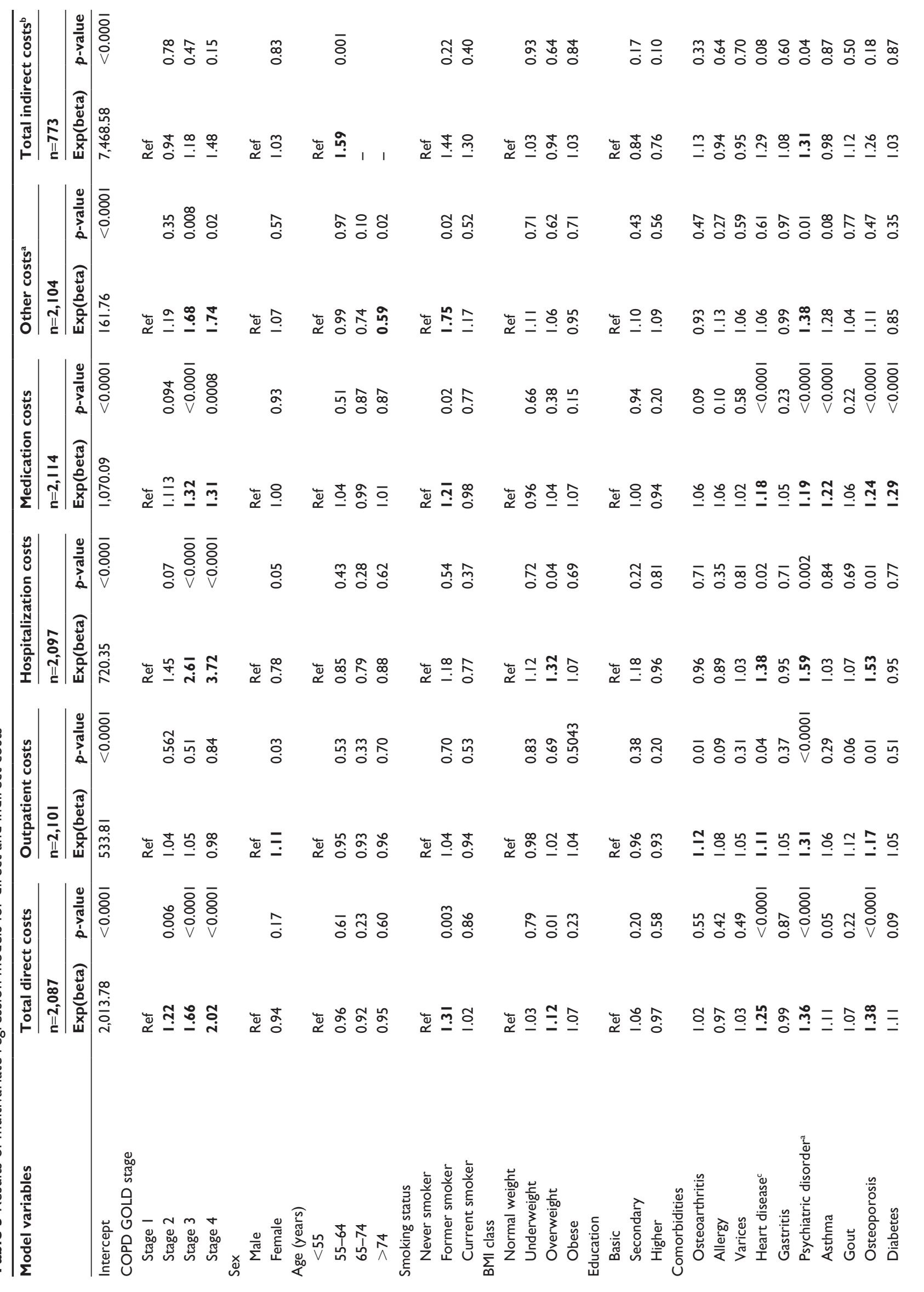




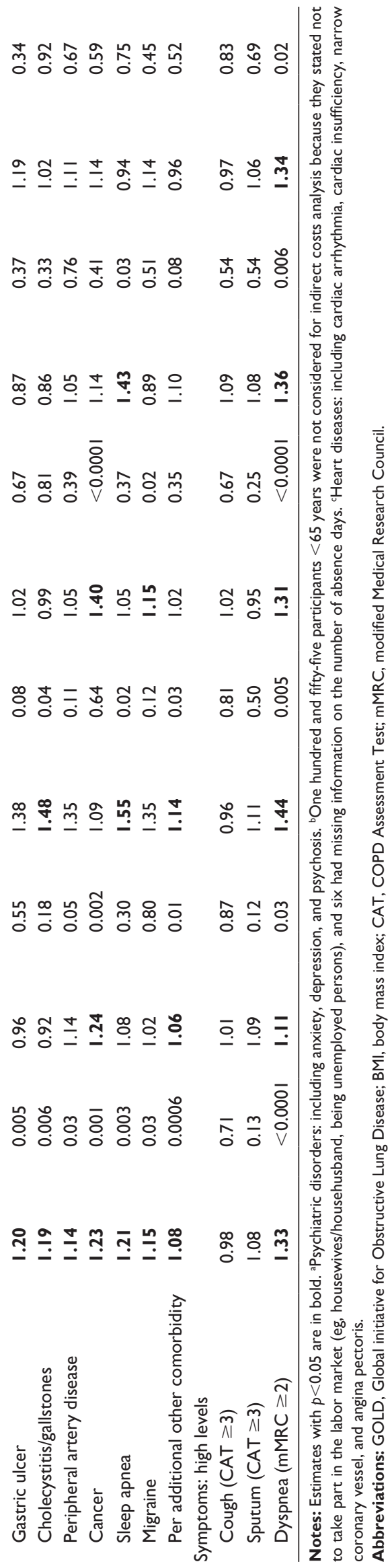

Table 4 Interactions between COPD stage, comorbidities, and dyspnea for annual direct or indirect costs

\begin{tabular}{|c|c|c|c|c|}
\hline \multirow[t]{3}{*}{ Model variables } & \multirow{2}{*}{\multicolumn{2}{|c|}{$\frac{\text { Direct costs }}{n=2,090}$}} & \multirow{2}{*}{\multicolumn{2}{|c|}{$\begin{array}{l}\text { Indirect costs } \\
\mathrm{n}=773\end{array}$}} \\
\hline & & & & \\
\hline & Exp(beta) & p-value & Exp(beta) & $p$-value \\
\hline \multicolumn{5}{|l|}{ COPD } \\
\hline Stage $1 / 2$ & Ref & & Ref & \\
\hline Stage $3 / 4$ & 1.69 & $<0.0001$ & 1.35 & 0.10 \\
\hline \multicolumn{5}{|l|}{ Comorbidities } \\
\hline Low number $(<3)$ & Ref & & Ref & \\
\hline High number $(\geq 3)$ & 1.83 & $<0.0001$ & 1.46 & 0.03 \\
\hline \multicolumn{5}{|l|}{ Dyspnea } \\
\hline Low level $(\mathrm{mMRC}<2)$ & Ref & & Ref & \\
\hline High level $(m M R C \geq 2)$ & 1.43 & $<0.0001$ & 1.46 & 0.10 \\
\hline \multicolumn{5}{|l|}{ Interactions } \\
\hline $\begin{array}{l}\text { COPD stage } 3 / 4 \\
\times \text { high number of } \\
\text { comorbidities }\end{array}$ & 0.72 & 0.0001 & 0.87 & 0.57 \\
\hline $\begin{array}{l}\text { COPD stage } 3 / 4 \\
\times \text { high level of dyspnea }\end{array}$ & 1.03 & 0.75 & 1.02 & 0.94 \\
\hline $\begin{array}{l}\text { High level of } \\
\text { dyspnea } \times \text { high number } \\
\text { of comorbidities }\end{array}$ & 1.05 & 0.56 & 0.90 & 0.68 \\
\hline
\end{tabular}

Notes: Models were adjusted for age group, sex, education, smoking status, and BMI class. Estimates with $p<0.05$ are in bold.

Abbreviation: mMRC, modified Medical Research Council.

showed the strongest driving effect on direct health care costs, whereas cough and sputum production were not associated with any incremental direct costs. When considering the most frequently reported comorbidities, osteoporosis, psychiatric disorders, heart disease, cancer, and sleep apnea were associated with significantly increased direct health care costs. However, the effect of higher COPD stages (GOLD 3/4) was greater than the effects of the presence of any comorbid condition. A sub-additive interaction between advanced COPD stage and a high number of comorbidities reduced the independent cost-driving effects of these factors and may be an indicator for possible ceiling effects of treatment.

For indirect costs, besides a high level of dyspnea, psychiatric disorders were identified as a driver of costs, whereas other comorbid conditions did not show significant associations. However, a higher number of comorbid conditions was associated with indirect costs. No statistically significant associations between cough or sputum production and indirect costs were observed, whereas higher age was associated with increased costs.

From an economic perspective, it is important to identify possible starting points to reduce the economic burden of COPD, and therefore, it is crucial to differentiate between the costs of COPD itself and costs of concomitant circumstances. 


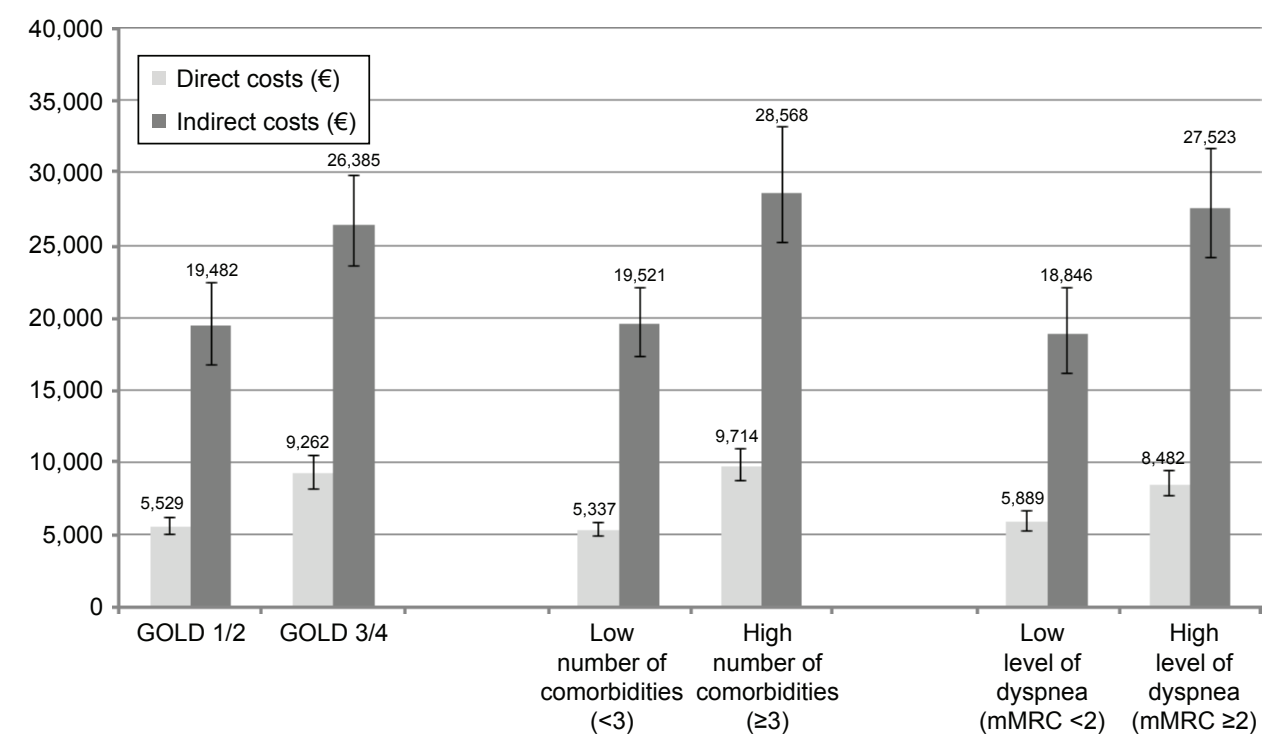

Figure 2 Adjusted mean total direct or indirect costs $(€)$ per year for subgroups.

Note: Means were adjusted according to regression models shown in Table 4.

Abbreviations: GOLD, Global initiative for Obstructive Lung Disease; mMRC, modified Medical Research Council.

Treating comorbidities and the symptoms that in patients with COPD drive costs is a first step, and has the potential to be cost-effective or even cost-saving, ${ }^{37,38}$ although economic evaluations may be challenging. ${ }^{39}$

The economic view on the burden of COPD does not necessarily contradict the patient's perspective. Comparing the most relevant comorbidities from an economic and patient perspective, a clear overlap is apparent: In a previous analysis of this dataset, among the most important comorbidities with negative effects on health-related quality of life were psychiatric disorders, peripheral artery disease, sleep apnea, and heart disease, all of which were also identified as major cost drivers in this analysis. ${ }^{40}$

Compared to previous studies, our results were consistent in that comorbidities in patients with COPD increase the direct costs, largely as a result of increasing health care utilization. ${ }^{16,18,19,41}$ However, there was a high variation in the effect on costs of different comorbidities. A review of the excess costs of comorbidities in COPD by Huber et al reported that pneumonia, cardiovascular disease, and diabetes were associated with the highest excess costs. ${ }^{18}$ Simon-Tuval et al found myocardial infarction, congestive heart failure, mild liver disease, and diabetes as the main cost drivers in patients with COPD. ${ }^{19}$ Mannino et al reported the highest effects on health care costs were for patients with COPD and comorbid cardiovascular disease, anemia, or chronic kidney disease, ${ }^{41}$ whereas Schwab et al reported the highest associations with all-cause health care costs were for congestive heart failure, cerebrovascular disease, coronary artery disease, sleep apnea, and depressive disorders. ${ }^{21}$ Osteoporosis, which showed the highest effect on direct costs in our analysis, has also been identified as an important contributor to cost in these previous studies ${ }^{21,41}$ and has recently gained increased interest in the management of patients with COPD. ${ }^{42,43}$

In terms of indirect costs, few studies have considered the effects of comorbidities in patients with COPD. ${ }^{18}$ It has been shown that although COPD patients have considerably higher indirect costs than lung-healthy controls, the effect of selected comorbid conditions on indirect costs does not necessarily differ between COPD patients and controls. ${ }^{3}$ In their analysis of productivity losses in COPD patients, Erdal et al considered the number of comorbid conditions instead of single conditions, and reported that the number of days with lost productivity increased by five per year per additional comorbidity added, ${ }^{44}$ which is in line with our finding that a high number of comorbidities shows a better association with indirect costs than single comorbid conditions.

The difficulty of these comparisons is that all studies considered different comorbidities with varying definitions, and often used other populations as reference. When considering all listed 33 comorbid conditions irrespective of their frequency in our analysis, multiple sclerosis $(+425 \%)$ and Parkinson's disease (+243\%) were by far the most expensive comorbid conditions. However, these rather rare conditions are not necessarily representative for patients with COPD, and so for our analysis, we focused on common comorbidities in COPD. When considering the most prevalent comorbidities only (lifetime prevalence $\geq 10 \%$, Figure 1 ), the effect size 
and statistical significance of the single conditions remained approximately the same compared to models considering all 33 comorbidities.

As to symptoms, previous studies have investigated their effect on health care utilization and costs, but studies considering cough and sputum production simultaneously or focusing on work absence or indirect costs are rare. Dyspnea, as the cardinal symptom of COPD, has been confirmed in numerous studies as a major cause of the disability associated with the disease, and as a main factor for reduced health-related quality of life or health utility of patients. ${ }^{45}$ Our analysis identified dyspnea as a major driver of health care utilization, especially of inpatient services, and indirect costs, whereas cough and sputum did not have any effects on either direct or indirect costs. Even if the cut-off points for the definition of cough and sputum production were increased within a sensitivity analysis from 3 to 4 in the CAT, there were no significant associations of cough or sputum with direct or indirect costs.

A previous study involving patients in Japan with COPD reported 52\% increased COPD management costs in those with $\mathrm{mMRC} \geq 2$, similar to the results we observed. ${ }^{25}$ Furthermore, Punekar et al have described sharply increasing health care costs with increasing dyspnea levels. ${ }^{46}$ However, these studies did not analyze the impact of cough or sputum on costs, although cough has been associated with worse health-related quality of life as well. ${ }^{47}$ Ding et al reported associations between a higher symptom burden (as defined by an increasing CAT score) and productivity loss in a pooled sample of patients consulting for routine care in Europe, the USA, and the People's Republic of China, but this study does not allow to disentangle the effects of the different aspects of the CAT. ${ }^{23}$ Although a difference in indirect cost of approximately $€ 8,700$ per year between the groups with low vs high levels of dyspnea was observed in our study when considering potential interactions, this difference did not reach statistical significance. This could be due to a low sample size of the indirect costs analysis or high variability within this group.

Finally, we found a significant association between former smoking and direct costs, whereas current smoking was not associated with higher costs. One could speculate that arising or worsening health problems may be the reason for smoking cessation and therefore the reason for higher costs than in never smokers or even current smokers. This phenomenon has been observed previously, ${ }^{48}$ and needs further investigation in longitudinal studies.

In comparison with previous studies, the strength of this study is that we included simultaneously a number of medically important comorbidities and symptoms as potential drivers of direct and indirect costs among patients with COPD, and put these aspects into context with the degree of airflow limitation. Furthermore, this study included patients with mild as well as severe or very severe airflow limitation, so that all GOLD stages were represented in an adequate frequency.

However, several limitations of our analysis have to be mentioned. First, central data are based on self-reported information by study participants, such as the presence of physician-diagnosed comorbidities ("Has a physician ever diagnosed you with ...?") and information on health care utilization and work absence due to illness. Comorbidity prevalence estimates may differ if, for example, medication data are used for the verification of comorbidities. ${ }^{49}$ Furthermore, no information on the severity of comorbid conditions was available. To minimize the problem of recall bias with regard to health care utilization, we used different recall periods for various health services which is an established method of collecting data on combined primary and secondary health care usage, and is one of the few ways of collecting indirect cost data. ${ }^{50}$ This approach for cost data collection has been shown to be valid. ${ }^{51}$ Second, medical aids, nursing, and alternative practitioners, together with over-the-counter and non-pharmacy medicines, were excluded from our analyses. Consequently, the economic cost burden of COPD could be underestimated.

Explicitly, we did not include exacerbation history as a possible cost driver in our analysis, because both costs data and exacerbation history were assessed retrospectively for the same time period and exacerbations and their severity levels are defined by health care utilization (eg, a severe exacerbation is defined by hospitalization). Therefore, our cost calculations include to a certain amount the costs of exacerbations, and controlling for exacerbations in regression analyses would introduce circularity problems within the models and reduce their validity.

Furthermore, the design of this study cannot be used to investigate if COPD-related costs are increased by comorbid conditions and whether these conditions have the same cost-driving effects in individuals with or without COPD. When focusing on costs for medications coded with ATC " $R$ " (respiratory system) as a proxy for COPD-related costs in an additional analysis, higher GOLD stages, asthma, sleep apnea, and dyspnea were identified as cost drivers. Other comorbid conditions did not show significant associations with this cost category, suggesting that costs of comorbidities may be comparable in individuals with or without COPD as 
previously suggested. ${ }^{3}$ However, especially in the case of COPD which is recognized as a systemic disease with extrapulmonary manifestations, it is challenging to disentangle disease-related costs from overall health care costs.

Nevertheless, our analysis illustrated the high prevalence of comorbidities among COPD patients, and their negative effects on the cost burden of COPD. This emphasizes the importance of a patient-centered, multidisciplinary collaboration in COPD management based on a broad range of interventions, ${ }^{52}$ and of further research to establish a holistic approach to prevent, treat, and reduce coexisting comorbidities and symptoms of COPD. ${ }^{10}$

Finally, our findings may be useful in decision-analytic models for cost-effectiveness analyses of COPD interventions. While older cost-effectiveness models focused on lung-function only, more contemporary models contain comorbidities and symptoms in the characterization of the disease. ${ }^{53-55}$ However, these models are in need of evidence on the relationship between costs and comorbid conditions or symptoms.

\section{Conclusion}

This study represents a comprehensive economic analysis of COPD in Germany, which includes patients with a high number of comorbidities and symptoms, clearly demonstrating their impact on direct and indirect costs. From a public health perspective, it is important to consider not only the management of COPD itself but also the identified primary cost drivers, and in particular, to reduce the burden due to comorbidities and dyspnea, which are also relevant from the patients' perspective.

\section{Acknowledgments}

This work was supported by the Competence Network Asthma and COPD (ASCONET). The COSYCONET COPD cohort is funded by the German Federal Ministry of Education and Research (BMBF) with grant numbers 01GI0881 and $01 \mathrm{GI0} 82$ and by unrestricted grants from various pharmaceutical companies. The authors would like to thank all study centers which contributed in patient recruitment and data collection/capture as listed on http://www.asconet.net/ html/cosyconet/studzent. Finally, they thank David Young of Young Medical Communications and Consulting Ltd for his critical review of the manuscript.

\section{Disclosure}

$\mathrm{CV}$ reports personal fees from the pharmaceutical companies Almirall, AstraZeneca, Boehringer Ingelheim, Chiesi,
GlaxoSmithKline, Janssen, Mundipharma, Novartis, Takeda, and Cipla, and grants and personal fees from Grifols outside the submitted work. The other authors report no conflicts of interest in this work.

\section{References}

1. Global Initiative for Chronic Obstructive Lung Disease (GOLD). Global strategy for the diagnosis, management, and prevention of chronic obstructive pulmonary disease (update 2017). 2017. Available from: http://www.goldcopd.org/. Accessed February 20, 2017.

2. Menn P, Heinrich J, Huber RM, et al; KORA Study Group. Direct medical costs of COPD - an excess cost approach based on two population-based studies. Respir Med. 2012;106(4):540-548.

3. Wacker ME, Jörres RA, Schulz H, et al; COSYCONET-Consortium. Direct and indirect costs of COPD and its comorbidities: results from the German COSYCONET study. Respir Med. 2016;111:39-46.

4. Ford ES, Murphy LB, Khavjou O, Giles WH, Holt JB, Croft JB. Total and state-specific medical and absenteeism costs of COPD among adults aged $\geq 18$ years in the United States for 2010 and projections through 2020. Chest. 2015;147(1):31-45.

5. Jansson SA, Backman H, Stenling A, Lindberg A, Rönmark E, Lundback B. Health economic costs of COPD in Sweden by disease severity - has it changed during a ten years period? Respir Med. 2013; 107(12):1931-1938.

6. European Respiratory Society. The European Lung White Book. 2nd revised ed. Sheffield: European Respiratory Society; 2013.

7. Gershon AS, Guan J, Victor JC, Goldstein R, To T. Quantifying health services use for chronic obstructive pulmonary disease. Am J Respir Crit Care Med. 2013;187(6):596-601.

8. McLean S, Hoogendoorn M, Hoogenveen RT, et al. Projecting the COPD population and costs in England and Scotland: 2011 to 2030. Sci Rep. 2016;6:31893.

9. Vogl M, Leidl R. Informing management on the future structure of hospital care: an extrapolation of trends in demand and costs in lung diseases. Eur J Health Econ. 2016;17(4):505-517.

10. Hillas G, Perlikos F, Tsiligianni I, Tzanakis N. Managing comorbidities in COPD. Int J Chron Obstruct Pulmon Dis. 2015;10:95-109.

11. Huber MB, Wacker ME, Vogelmeier CF, Leidl R. Comorbid influences on generic health-related quality of life in COPD: a systematic review. PLoS One. 2015;10(7):e0132670.

12. Wacker ME, Jörres RA, Karch A, et al; COSYCONET study group. Relative impact of COPD and comorbidities on generic health-related quality of life: a pooled analysis of the COSYCONET patient cohort and control subjects from the KORA and SHIP studies. Respir Res. 2016;17(1):81.

13. Divo M, Cote C, de Torres JP, et al; BODE Collaborative Group. Comorbidities and risk of mortality in patients with chronic obstructive pulmonary disease. Am J Respir Crit Care Med. 2012;186(2):155-161.

14. Miller J, Edwards LD, Agustí A, et al; Evaluation of COPD Longitudinally to Identify Predictive Surrogate Endpoints (ECLIPSE) Investigators. Comorbidity, systemic inflammation and outcomes in the ECLIPSE cohort. Respir Med. 2013;107(9):1376-1384.

15. Gershon AS, Mecredy GC, Guan J, Victor JC, Goldstein R, To T. Quantifying comorbidity in individuals with COPD: a population study. Eur Respir J. 2015;45(1):51-59.

16. Jansson SA, Backman H, Ronmark E, Lundbäck B, Lindberg A. Hospitalization due to co-morbid conditions is the main cost driver among subjects with COPD-a report from the population-based OLIN COPD study. COPD. 2015;12(4):381-389.

17. Westney G, Foreman MG, Xu J, Henriques King M, Flenaugh E, Rust G. Impact of comorbidities among Medicaid enrollees with chronic obstructive pulmonary disease, United States, 2009. Prev Chronic Dis. 2017;14:E31.

18. Huber MB, Wacker ME, Vogelmeier CF, Leidl R. Excess costs of comorbidities in chronic obstructive pulmonary disease: a systematic review. PLoS One. 2015;10(4):e0123292. 
19. Simon-Tuval T, Scharf SM, Maimon N, Bernhard-Scharf BJ, Reuveni H, Tarasiuk A. Determinants of elevated healthcare utilization in patients with COPD. Respir Res. 2011;12:7.

20. Schwarzkopf L, Wacker M, Ertl J, Hapfelmeier J, Larisch K, Leidl R. Impact of chronic ischemic heart disease on the health care costs of COPD patients - an analysis of German claims data. Respir Med. 2016; 118:112-118.

21. Schwab P, Dhamane AD, Hopson SD, et al. Impact of comorbid conditions in COPD patients on health care resource utilization and costs in a predominantly Medicare population. Int J Chron Obstruct Pulmon Dis. 2017;12:735-744.

22. Deniz S, Şengül A, Aydemir Y, Çeldir Emre J, Özhan MH. Clinical factors and comorbidities affecting the cost of hospital-treated COPD. Int J Chron Obstruct Pulmon Dis. 2016;11:3023-3030.

23. Ding B, Small M, Bergström G, Holmgren U. COPD symptom burden: impact on health care resource utilization, and work and activity impairment. Int J Chron Obstruct Pulmon Dis. 2017;12:677-689.

24. Foo J, Landis SH, Maskell J, et al. Continuing to confront COPD International Patient Survey: economic impact of COPD in 12 countries. PLoS One. 2016;11(4):e0152618.

25. Small M, Holbrook T, Wood R, Mullerova H, Naya I, Punekar YS. Prevalence and burden of dyspnoea among COPD patients in Japan. Int J Clin Pract. 2016;70(8):676-681.

26. Karch A, Vogelmeier C, Welte T, et al; COSYCONET Study Group. The German COPD cohort COSYCONET: aims, methods and descriptive analysis of the study population at baseline. Respir Med. 2016;114:27-37.

27. Jörres RA, Welte T, Bals R, Koch A, Schnoor M, Vogelmeier C. Einfluss systemischer Manifestationen und Komorbiditäten auf den klinischen Zustand und den Verlauf bei COPD [Systemic manifestations and comorbidities in patients with chronic obstructive pulmonary disease (COPD) and their effect on clinical state and course of the disease - an overview of the cohort study COSYCONET]. Dtsch Med Wochenschr. 2010;135(10):446-449. German.

28. Quanjer PH, Stanojevic S, Cole TJ, et al; ERS Global Lung Function Initiative. Multi-ethnic reference values for spirometry for the 3-95-yr age range: the global lung function 2012 equations. Eur Respir J. 2012; 40(6):1324-1343.

29. Karl FM, Holle R, Bals R, et al; COSYCONET Study Group. Costs and health-related quality of life in Alpha-1-Antitrypsin Deficient COPD patients. Respir Res. 2017;18(1):60.

30. Bock JO, Brettschneider C, Seidl H, et al. [Calculation of standardised unit costs from a societal perspective for health economic evaluation]. Gesundheitswesen. 2015;77(1):53-61. German.

31. WHO Collaborating Centre for Drug Statistics Methodology. Guidelines for ATC Classification and DDD Assignment 2010. Oslo: WHOCC; 2009.

32. Wissenschaftliches Institut der AOK (WIdO). Available from: http:// wido.de/arzneimittel.html. Accessed May 20, 2011. German.

33. Federal Statistical Office. Statistical Yearbook 2013 for the Federal Republic of Germany. Wiesbaden: Federal Statistical Office; 2014.

34. Institute for Employment Research (IAB) of the German Federal Employment Agency (BA). IAB brief reports no. 18. Nuremberg: IAB; 2014.

35. Jones PW, Harding G, Berry P, Wiklund I, Chen WH, Kline Leidy N. Development and first validation of the COPD Assessment Test. Eur Respir J. 2009;34(3):648-654.

36. Putcha N, Puhan MA, Drummond MB, et al. A simplified score to quantify comorbidity in COPD. PLoS One. 2014;9(12):e114438.

37. Boland MR, Kruis AL, Tsiachristas A, et al. Cost-effectiveness of integrated COPD care: the RECODE cluster randomised trial. BMJ Open. 2015;5(10):e007284.
38. Boland MR, Tsiachristas A, Kruis AL, Chavannes NH, Rutten-van Molken MP. The health economic impact of disease management programs for COPD: a systematic literature review and meta-analysis. BMC Pulm Med. 2013;13:40.

39. McPhail SM. Multimorbidity in chronic disease: impact on health care resources and costs. Risk Manag Healthc Policy. 2016;9:143-156.

40. Wacker ME, Jörres RA, Karch A, et al. Assessing health-related quality of life in COPD: comparing generic and disease-specific instruments with focus on comorbidities. BMC Pulm Med. 2016;16(1):70.

41. Mannino DM, Higuchi K, Yu TC, et al. Economic burden of COPD in the presence of comorbidities. Chest. 2015;148(1):138-150.

42. Inoue D, Watanabe R, Okazaki R. COPD and osteoporosis: links, risks, and treatment challenges. Int J Chron Obstruct Pulmon Dis. 2016;11: 637-648.

43. Okazaki R, Watanabe R, Inoue D. Osteoporosis associated with chronic obstructive pulmonary disease. J Bone Metab. 2016;23(3):111-120.

44. Erdal M, Johannessen A, Askildsen JE, Eagan T, Gulsvik A, Grøonseth R. Productivity losses in chronic obstructive pulmonary disease: a population-based survey. BMJ Open Respir Res. 2014;1(1):e000049.

45. Miravitlles M, Huerta A, Valle M, et al. Clinical variables impacting on the estimation of utilities in chronic obstructive pulmonary disease. Int J Chron Obstruct Pulmon Dis. 2015;10:367-377.

46. Punekar YS, Wurst K, Shukla A. Resource use and costs up to two years post diagnosis among newly diagnosed COPD patients in the UK primary care setting: a retrospective cohort study. COPD. 2015;12(3): 267-275.

47. Deslee G, Burgel PR, Escamilla R, et al. Impact of current cough on health-related quality of life in patients with COPD. Int J Chron Obstruct Pulmon Dis. 2016;11:2091-2097.

48. Wacker M, Holle R, Heinrich J, et al. The association of smoking status with healthcare utilisation, productivity loss and resulting costs: results from the population-based KORA F4 study. BMC Health Serv Res. $2013 ; 13: 278$.

49. Lucke T, Herrera R, Wacker M, et al; COSYCONET-Consortium. Systematic analysis of self-reported comorbidities in large cohort studies - a novel stepwise approach by evaluation of medication. PLoS One. 2016;11(10):e0163408.

50. Evans C, Crawford B. Patient self-reports in pharmacoeconomic studies. Their use and impact on study validity. Pharmacoeconomics. 1999; 15(3):241-256.

51. Seidl H, Meisinger C, Wende R, Holle R. Empirical analysis shows reduced cost data collection may be an efficient method in economic clinical trials. BMC Health Serv Res. 2012;12:318.

52. Vanfleteren LE, Spruit MA, Wouters EF, Franssen FM. Management of chronic obstructive pulmonary disease beyond the lungs. Lancet Respir Med. 2016;4(11):911-924.

53. Briggs A, Baker T, Risebrough NA, et al. Development of the galaxy chronic obstructive pulmonary disease (COPD) model using data from ECLIPSE: internal validation of a linked-equations cohort model. Med Decis Making. 2017;37(4):469-480.

54. Hoogendoorn M, Feenstra TL, Asukai Y, et al. Patient heterogeneity in health economic decision models for chronic obstructive pulmonary disease: are current models suitable to evaluate personalized medicine? Value Health. 2016;19(6):800-810.

55. Asukai Y, Baldwin M, Fonseca T, Gray A, Mungapen L, Price D. Improving clinical reality in chronic obstructive pulmonary disease economic modelling: development and validation of a micro-simulation approach. Pharmacoeconomics. 2013;31(2):151-161. 


\section{Supplementary material}

Table SI German unit costs

\begin{tabular}{|c|c|}
\hline Sources of costs & $\begin{array}{l}\text { Unit costs }(€) \\
\text { per day/visit }\end{array}$ \\
\hline \multicolumn{2}{|l|}{ Direct costs categories } \\
\hline GP or GP for internal medicine & 20.22 \\
\hline \multicolumn{2}{|l|}{ Specialists } \\
\hline $\begin{array}{l}\text { Specialist for internal medicine } \\
\text { (including pneumologist) }\end{array}$ & 64.65 \\
\hline Gynecologist & 30.53 \\
\hline Ophthalmologist & 35.09 \\
\hline Orthopedist & 25.27 \\
\hline Otorhinolaryngologist & 27.55 \\
\hline Surgeon & 44.11 \\
\hline Dermatologist & 19.10 \\
\hline Radiologist & 43.97 \\
\hline Urologist & 24.97 \\
\hline Neurologist/psychiatrist/psychotherapist & 45.58 \\
\hline Specialist in occupational medicine & 20.22 \\
\hline $\begin{array}{l}\text { Other physician (including ambulant } \\
\text { hospital visits) }\end{array}$ & 43.97 \\
\hline \multicolumn{2}{|l|}{ Rehabilitation } \\
\hline Ambulant visit & 48.29 \\
\hline Inpatient rehabilitation & 122.09 \\
\hline \multicolumn{2}{|l|}{ Hospital treatment } \\
\hline Ambulant visit & 43.97 \\
\hline Inpatient hospital & 589.32 \\
\hline Physiotherapist & 16.62 \\
\hline Prescribed pharmaceuticals & AOK Institute \\
\hline \multicolumn{2}{|l|}{ Indirect cost categories ${ }^{\mathrm{a}}$} \\
\hline Work absence ${ }^{b}$ & $|77.2|$ \\
\hline Premature retirement & 37,126 (per year) \\
\hline
\end{tabular}

Notes: German unit costs by Bock et al' were calculated based on regularly published sources from different players in the German health care system (mainly accounting data and official statistics; differences between statutory and private health insurance were considered) and represent an approximation of societal opportunity cost. An annual update is provided by Bock et al. andirect costs only for subjects of employable age $<65$ years. ${ }^{\text {bW }}$ Work absence only for full-time and regular part-time employees.

Abbreviation: GP, general practitioner.

\section{Reference}

1. Bock JO, Brettschneider C, Seidl H, et al. [Calculation of standardised unit costs from a societal perspective for health economic evaluation]. Gesundheitswesen. 2015;77(1):53-61. German.

\section{Publish your work in this journal}

The International Journal of COPD is an international, peer-reviewed journal of therapeutics and pharmacology focusing on concise rapid reporting of clinical studies and reviews in COPD. Special focus is given to the pathophysiological processes underlying the disease, intervention programs, patient focused education, and self management protocols.

\section{Dovepress}

This journal is indexed on PubMed Central, MedLine and CAS. The manuscript management system is completely online and includes a very quick and fair peer-review system, which is all easy to use. Visit http://www.dovepress.com/testimonials.php to read real quotes from published authors. 